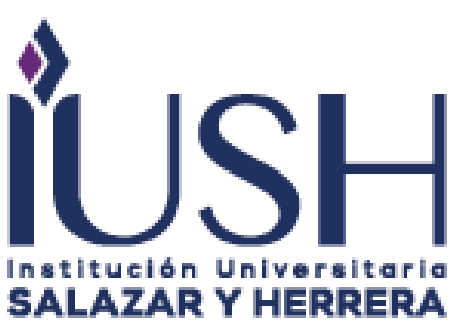

QUID 2017, pp. 1789-1794, Special Issue N¹- ISSN: 1692-343X, Medellín-Colombia

\title{
MODELING OF PURCHASING MANAGERS' INDEX OF THE REGION AND ASSESSMENT OF \\ ITS INFLUENCE ON PARAMETERS OF DEVELOPMENT OF INDUSTRIAL SECTORS OF ECONOMY (ON THE EXAMPLE OF REGIONS OF THE VOLGA FEDERAL DISTRICT)
}

(Recibido el 01-06-2017. Aprobado el 09-08-2017)

\author{
Marat Rashitovich Safiullin \\ Kazan Federal University, the vice rector of the \\ Kazan federal university concerning economic and \\ strategic development, leonid.Elshin@tatar.ru
}

\author{
Leonid Alekseevich Elshin \\ Kazan Federal University, Center of strategic \\ estimates and forecasts of Institute of management, \\ economy and finance; State Budgetary Institution \\ Center of Perspective Economic Researches of \\ Academy of Sciences of the Republic of Tatarstan
}

\begin{abstract}
Annotation. The investigation of business movement at the territorial level is a critical logical and methodological issue, the arrangement of which has not discovered a for the most part acknowledged way to deal with the present time. The look for strategies went for recognizing the effect of local business action on the improvement parameters of individual segments of economy is a similarly critical issue, both in the logical intellectual and in down to earth terms. This article is dedicated to settling these issues. The subject of study is the strategies for deciding and displaying the business movement of the district and evaluating its effect on the improvement parameters of specific sorts of financial action. The creators consider in detail such parts of a theme as the recognizable proof of variables that frame the improvement parameters of business action of local monetary frameworks, the examination of intraregional highlights that decide the adjustment in the directions of business action records, communicating the adjustment in the desires of financial specialists in a concentrated shape. Specific consideration is paid to the issues of monetary and numerical demonstrating of the effect level of consistently produced inclines in the business action of the area on the advancement direction of specific sorts of mechanical economy of the locale. Within the framework of the constructed system of regional indices, we tested the concept of determining the level of their influence on the development parameters of certain industrial sectors of the economy of regional economic systems of the Volga Federal District.
\end{abstract}

Key words: business activity of the region, modeling and forecasting, industrial sectors of the region's economy, competitiveness and sustainability of regional systems

Citar, estilo APA: Safiullin, M. \& Elshin, L. (2017). Modeling of purchasing managers' index of the region and assessment of its influence on parameters of development of industrial sectors of economy (on the example of regions of the Volga federal district). Revista QUID (Special Issue), 1789-1794. 


\section{INTRODUCTION}

There are a few cases of the aggregation and production of files surveying business and monetary movement at the national level in Russia: the entrepreneurial certainty file, the business action file of the Relationship of Administrators of Russia (AMR), the file of entrepreneurial desires and others (Anoshin, 2004) (Zilbershtein and Chebotareva, 2010). At the local level, this work is for all intents and purposes not did. In the mean time, the local economy is gone up against with its own specific arrangement of issues because of the course and specificity of the economy of every specific domain, and it isn't completely right to utilize the macroeconomic (national) level pointers to survey the local economy (Zhikharevich, 2011) (Safiullin, Elshin and Prygunova, 2016). In this manner, it is important to build up an exceptional arrangement of meso-level pointers that would consider the specifics of elements and components for the improvement of individual local monetary frameworks, and also would shape the reason for the advancement and logical legitimization of prescient evaluations of their improvement in the states of vertical and flat combination into the full scale and meso-level included esteem development framework.

Considering that the districts, for an assortment of reasons, adjust contrastingly and respond to any progressions happening, including inside the national as well as worldwide financial condition, the nature and directions of their improvement will have customized highlights, including business action of their frameworks (Modigliani and Brumberg, 1954) (Robert, 1976). Consequently, the top to bottom investigation of business movement at the provincial level requires a basic examination of an extensive variety of variables that decide its affectability to them, and additionally foreordain the arrangement of channels for the spread of business action of other monetary frameworks that are commonly coordinated into a specific local economy. Comprehension and logical substantiation of this procedure will permit enhancing the arrangement of various issues (in the field of direction and "manual administration" of the recurrent improvement periods of business action of the district) on account of infrequent need to grant extra motivations smoothing emergency periods of here and now financial cycles, produced because of progressive changes of business condition parameters.

It is likewise critical that right now the hypothesis of territorial economy has not in any case shaped a solitary methodological approach that uncovers the highlights of measuring, surveying and looking at the business action with regards to individual provincial financial frameworks, including their interrelations at the full scale and meso-level (Russell and Russell, 1999) (Kydland and Prescott, 1982) (Prescott, E. (1986).

\section{MATERIALS AND METHODS}

As we would like to think, it is conceivable to understand the assignment postured by the intricate recognizable proof of desires of the financial operators in a concentrated frame communicating business movement in the short-, medium-and long haul prospects, creating thusly the monetary cycles of the districts of the comparing plentifulness. In the event that the desires can be communicated in a solitary arrangement of factual estimation, at that point their examination in the regional (level) and macroeconomic (vertical) areas makes it conceivable to find the idea of interrelations between them. Without a doubt, the proposed theory of settling the errand of finding the relationship nature between the business exercises of various regional (and progressive) levels requires, notwithstanding its immediate defense, the improvement of a methodological apparatus shaping the premise of the confirmation base.

We will comprehend the composite (vital) business action list as a mind boggling marker ascertained on the premise of a blend of relative estimations of various measurable pointers. Every part in the summing up record might have its own weight. The estimations of weight proportions might be resolved on the premise of an adequately extensive variety of techniques utilized as a part of the hypothesis of measurable investigation (for instance, they may incorporate strategies for relationship and factor examination, positioning parameters, understanding scientific programming errands, and so on.) (Robert, 1980). In this examination we utilized the taxonomical investigation strategies in evaluating the weight proportions for sub-lists framing the reason for figuring the fundamental estimations of the business action list of the area. In a concentrated 
shape, the calculation for deciding the business action records in the district is appeared in Figure

Preliminary selection of indicators characterizing meso-and macroeconomic shifts at the regional level

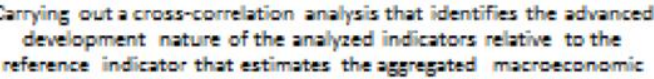

Grouping the indicators corresponding to the requirement of their advanced development relative to the reference statistical series, to homogeneous groups characterizing the current and prospective states in the capital markets, financial markets of meso-and macrolevels, as well as reflecting the development parameters of the resourceproduction potential of the regional economic system

Implementation of the "smogthing" procedure of the obtained statistical series, which estimate the values of the received subindices

Determination of values of weight ratios at the aggregated subindex values by the taxonomic analysis method

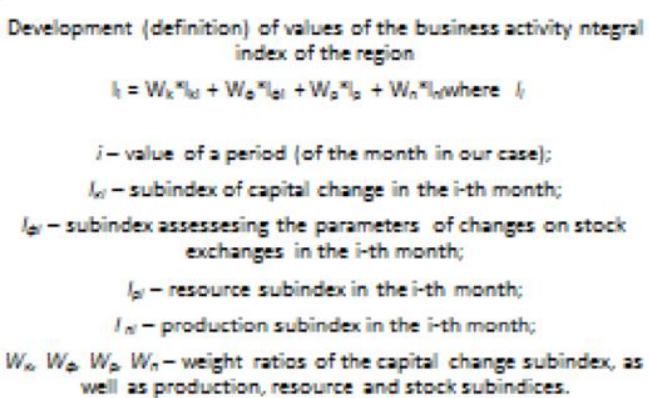

Figure 1 - Algorithm for determining the integral values of the business activity indices in the region

While picking the macroeconomic markers that are the reason for evaluating the business movement list in the area, it merits considering that in a genuine circumstance, a few pointers can be traded, supplemented, rejected relying upon the monetary approach and the financial advancement nature of the protest under investigation, and additionally the accessibility of measurable base on the vital financial markers.

\section{Results}

The calculated sub-index values for the Republic of Tatarstan are shown in Table 1.
Table 1: Calculation of sub-indices - four components of the "Regional Business Activity Index"

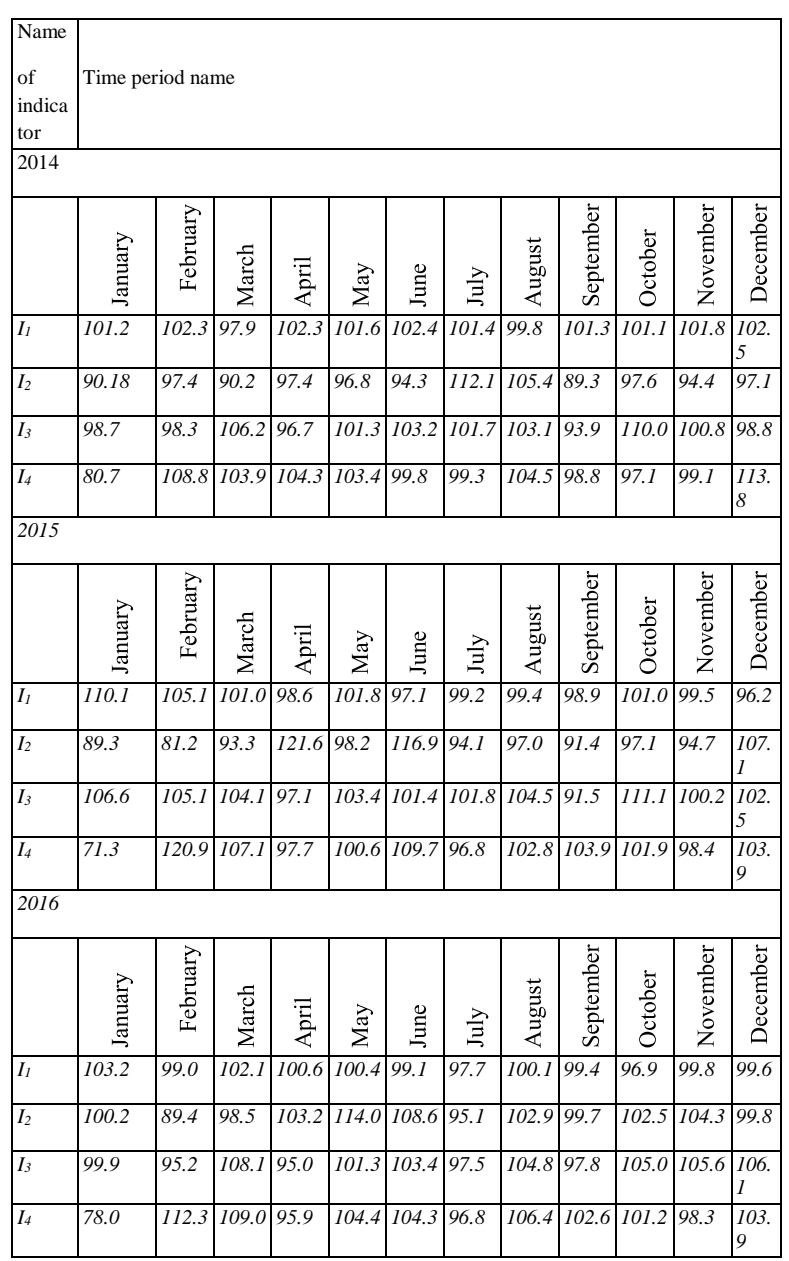

After the methodology of regular smoothing of the framed time arrangement describing the progression of the particular sub-lists, it wound up plainly conceivable to continue to the estimation of the last composite file of business action in the district. The composite Provincial Business Movement File (RBA) is made out of the figured arrangement of pointers or sub-lists of business action, considering beforehand characterized estimations of their weighting factors.

The aftereffects of the executed estimations (in light of the ordered examination strategies) portraying the particular weights of the separate sub-records associated with the assurance of indispensable 
estimations of the business movement file in the area are determined in Table

2.

Table 2: Values of the weighting ratios of the composite index sub-indices of business activity in the region

\begin{tabular}{|l|c|}
\hline \multicolumn{1}{|c|}{ Sub-index name } & Value of the weight assigned \\
\hline Capital sub-index & 0.278 \\
\hline Stock sub-index & 0.364 \\
\hline Production sub-index & 0.205 \\
\hline Resource sub-index & 0.153 \\
\hline
\end{tabular}

The utilization of acquired benefits of weighting proportions in the model for deciding the RBA file, and additionally the estimations of the relating subrecords got prior, has made it conceivable to do last figurings, the consequences of which are appeared in Figure 2.

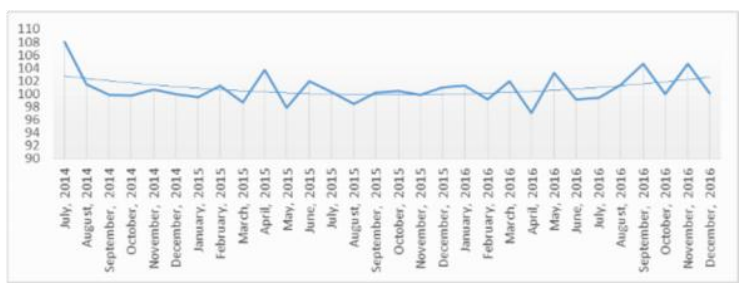

Figure 2. Dynamics of the business activity regional index of the Republic of Tatarstan, 2014-2016.

As per the graphical outline of the business movement progression, we can watch its lessening down to the finish of 2015 - the start of 2016, with its ensuing recuperation and change to the development stage from the finish of the first - the start of the second quarter of 2016. The negative elements of a pattern of the dynamic arrangement under thought was caused by basic issues that had aggregated in past periods. Their disturbance was all the more obviously showed as a change consequence of conjuncture and essential administration conditions in the time of 2014 center of 2016. Nonetheless, the usage of various state program measures went for supporting the money related area, change to a coasting rouble conversion standard, and so on., to a great extent added to the adjustment of financial specialists to the new settled substances, which was reflected experiencing significant change from the period of negative flow of business movement to positive. This is affirmed by the polynomial bend development saw from February to Walk 2016, which describes the developing pattern of the marker being referred to.

Having connected the created methodological methodologies, the creators evaluated the markers that decide the estimations of a composite business movement file with regards to the areas of the Volga Government Region (Figure 3).

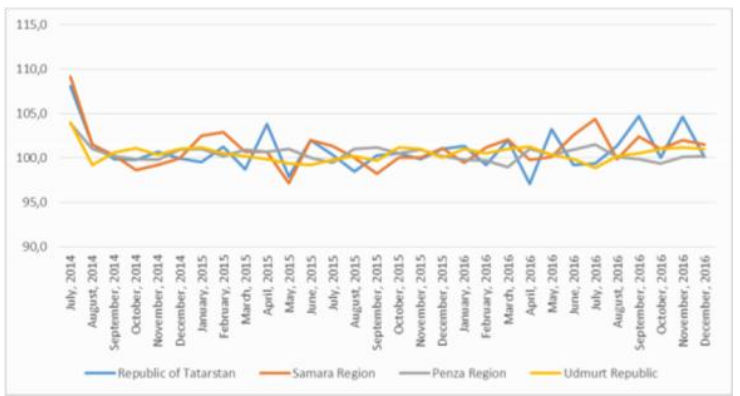

Figure 3. Dynamics of the business activity index in the regions of the Volga Federal District

The information introduced in the figure, which uncover the elements of business movement with regards to the concentrated arrangement of locales, exhibit their separated nature, however in the meantime, remaining inside the general collected pattern. The distributed simplification in the elements of the marker under investigation is communicated in the way that all areas considered here have been producing a difference in two stage shifts amid 20142016. The principal period of the business movement decay (W-formed) is settled in the period from Walk, 2014 to January, 2016, with the resulting change to the recuperation stage (Figure 4 ).

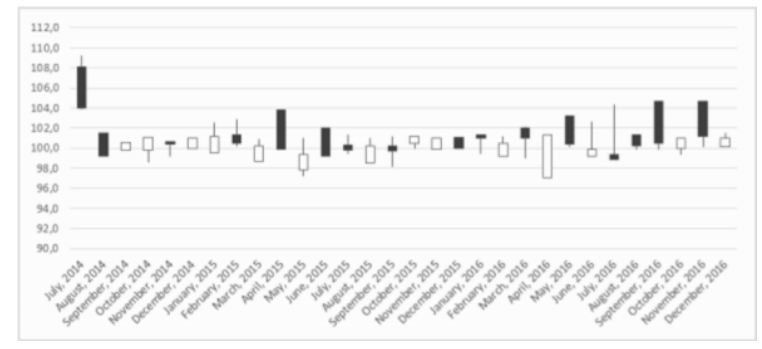

Figure 4. Aggregate trend of business activity dynamics of the set of studied regions of the Volga Federal District

Notwithstanding the distinguished comparable patterns in the arrangement and age of business action in the examined areas of the Volga Government Locale, their realistic understanding exceptionally recognizes their offensive directions. In the meantime, it is imperative that the districts portrayed by a more elevated amount of auxiliary and monetary improvement exhibit a larger 
amount of instability in the RBA file. Besides, the business movement of these districts is most vulnerable to changes saw in the outside and inner condition. Then, the locales with less articulated expansion of basic and financial improvement are less touchy to the changing parameters of the institutional and conjuncture arrange. In light of the figured information, we can express their larger amount of protection from various types of driving forces setting off the instruments for changing desires and business action of financial operators.

The designated reaction separation of monetary operators of individual territorial financial frameworks to different sorts of changes created in the outside and interior markets predetermines and realizes the arrangement of an assignment went for distinguishing and examining the affectability of specific parts of the locale's economy to the changing parameters of business action.

There are the connection investigation comes about beneath (Table 4) that builds up the connection between two broke down measurable arrangement - the development rates of the RBA file and the development rates of mechanical divisions of the economy. The parameters of the investigated arrangement are communicated in month to month development rates and incorporate information for the period from 2014 to 2016.

Table 4: Values of correlation ratios assessing the relationship tightness between the growth rate dynamics of the composite business activity index and the growth rates of industrial sectors of the regional economy

\begin{tabular}{|c|l|c|c|c|c|}
\hline \multirow{2}{*}{ No. } & \multirow{2}{*}{$\begin{array}{c}\text { Name of } \\
\text { indicator } \\
\text { studied }\end{array}$} & $\begin{array}{c}\text { Correlation ratio value } \\
\text { Tepublic of } \\
\text { Tatarstan }\end{array}$ & $\begin{array}{c}\text { Samara } \\
\text { Region }\end{array}$ & $\begin{array}{c}\text { Penza } \\
\text { Region }\end{array}$ & $\begin{array}{c}\text { Udmurt } \\
\text { Republic }\end{array}$ \\
\hline 1 & $\begin{array}{l}\text { Industrial } \\
\text { production }\end{array}$ & 0.667 & 0.753 & 0.661 & 0.607 \\
\hline 2 & $\begin{array}{l}\text { Mining } \\
\text { process }\end{array}$ & 0.401 & 0.379 & 0.456 & 0.547 \\
\hline 3 & $\begin{array}{l}\text { Manufacturing } \\
\text { processes }\end{array}$ & 0.723 & 0.815 & 0.697 & 0.581 \\
\hline 4 & $\begin{array}{l}\text { Production and } \\
\text { distribution of } \\
\text { electricity, gas } \\
\text { and water }\end{array}$ & 0.377 & 0.472 & 0.371 & 0.356 \\
\hline
\end{tabular}

The biggest estimation of the connection proportion between the RBA list and the relating modern part of the area's economy is had by the assembling segment. Along these lines, the demonstrating and approval of the appraisal of the impact level of monetary specialists' desires on the parameters of financial improvement were completed with regards to this sort of modern generation.

Table 5 presents demonstrate counts portraying the fundamental parameters of the relapse conditions got, which appraise the connection between the flow of mechanical development in the assembling part and the RBA file. The displayed computation comes about show the consistency of the models developed (criteria - values not as much as the predefined noteworthiness level of 0.05).

Table 5 Ratio values and their statistical significance

\begin{tabular}{|c|c|c|c|c|c|c|}
\hline & Y-crossing & $\begin{array}{c}\mathrm{P}- \\
\text { value } \\
(\mathrm{p}= \\
0.05)\end{array}$ & $\begin{array}{c}\mathrm{P} \\
(\text { lag } \\
\text { value })\end{array}$ & $\begin{array}{c}\mathrm{P}- \\
\text { value } \\
(\mathrm{p} \\
=\end{array}$ & $\begin{array}{c}\text { IDA } \\
\text { (lag } \\
\text { value })\end{array}$ & $\begin{array}{c}\mathrm{P} \\
\text { value } \\
(\mathrm{p}= \\
0.05)\end{array}$ \\
\hline $\begin{array}{c}\text { Republic } \\
\text { of } \\
\text { Tatarstan }\end{array}$ & 70.89 & 0.00 & 0.231 & 0.00 & 0.089 & 0.03 \\
\hline $\begin{array}{c}\text { Samara } \\
\text { Region }\end{array}$ & 54.23 & 0.00 & 0.35 & 0.03 & 0.99 & 0.00 \\
\hline $\begin{array}{c}\text { Penza } \\
\text { Region }\end{array}$ & 269.01 & 0.39 & 0.02 & 0.066 & 0.00 \\
\hline $\begin{array}{c}\text { Udmurt } \\
\text { Republic }\end{array}$ & 70.02 & 0.00 & 0.29 & 0.051 & 0.053 & 0.04 \\
\hline
\end{tabular}

where

$\mathrm{P}$ - growth rates of the manufacturing industry in the region (smoothed series);

IDA - growth rates of the composite business activity index in the region.

\section{CONCLUSIONS}

The estimation comes about demonstrate that the economy of the locales of the Volga Government Area has a connection mirroring the reliance of the development rates of assembling industry on the flow of changing the business action records. In the meantime, the level of relationship snugness in the locales with a less financial potential (Penza District, Udmurt Republic) is substantially less than the comparative esteems regular for the Republic of Tatarstan and the Samara Area. This may imply that the structure of assembling ventures in the locales examined has no consistency in reacting to changes in business action. Therefore, it can be contended that the elements of manageable advancement of specific sorts of creation specifically and territorial frameworks when all is said in done to a great extent relies upon the outside "driving forces" producing the structure and nature of the desires of financial specialists. 
In the meantime, as the evaluations and computations have appeared, the locales with less articulated social and monetary potential are more impervious to the unpredictability of variables produced in the outer and inward markets, which is affirmed by a lower level of versatility proportions under relating exogenous elements (RBA list) of a relapse display. Nonetheless, it ought to be noticed that their weaker combination into the arrangement of conceptive chains and agreeable connections of the national and worldwide levels, frames an arrangement of dangers communicated in impeded financial advancement in the states of stable parameters of the outer and inner condition (Bodrunov, Grinberg, and Sorokin, 2015).

\section{SUMMARY}

Taking everything into account, it ought to be noticed that the created methodological approach makes it conceivable to assess the level of response of specific sorts of financial action from the effect on the provincial and national monetary frameworks of the parameters of institutional and conjuncture arrange. In the meantime, the proportion esteems demonstrating the flexibility of the endogenous parameters contemplated because of present and forthcoming acclimations to the desires of financial specialists may to a great extent show the powerlessness level of different monetary exercises to different effects (Bodrunov, Grinberg, and Sorokin, 2015). Subsequently, it is conceivable to judge the present and forthcoming intensity levels of the provincial sectoral exercises, as well as of the whole area all in all. This, thus, shapes a huge logical and functional potential for the advancement of adjusted estimate models.

\section{ACKNOWLEDGEMENTS}

The work is performed according to the Russian Government Program of Competitive Growth of Kazan Federal University (26.8732.2017/8.9).

The publication was prepared within the framework of the scientific project No.16-0600062 supported by the Russian Foundation for Basic Research.

\section{REFERENCES}

Anoshin, I. (2004). Business Activity Indices in Russi. Macroeconomics. 10(12), 20-21.

Bodrunov, S. D., Grinberg, R. S. \& Sorokin, D. Ye. (2015). Economic System of Modern Russia:
Anatomy of the Present, Alternatives of the Future. Lomonosov, Moscow State University. p. 402.

Kydland, F. \& Prescott, E. (1982). Time to Build and Aggregate Fluctuations. Econometrica 50, 13451370

Modigliani, F. \& Brumberg, R. (1954). Utility Analysis and the Consumption Function: An Interpretation of Cross-Sectional Data. In Kurihara, K. K. PostKeynesian Economics, p. 388-436. New Brunswick, Rutgers University Press.

Prescott, E (1986). Theory Ahead of Business-Cycle Measurement. Carnegie-Rochester Series on Public Policy 25, p. 11-44.

Robert E. (1976). Econometric Policy Evaluation: A Critique. Carnegie-Rochester Series on Public Policy 1.

Robert, L. (1980). Methods and Problems in Business Cycle Theory. Journal of Money, Credit and Banking 12(4), 696-715

Russell C. \& Russell W. M. (1999). Population Crises and Population cycles. London: Galton Institute.

Safiullin, M., Elshin, L. \& Prygunova M. (2016). Methodological approaches to forecasting the midterm cycles of economic systems with the predominant type of administrative-command control. Journal of Economics and Economic Education, 17(Special issue 2), 277-287

Zhikharevich, B.S. (2011) Institutional Dimension of Regional Socio-Economic Space: Approach to Research. Economics of the North-West: Problems and Prospects, 2(3), 47.

Zilbershtein, L.V. \& Chebotareva, E. V. (2010). Development of Business and Economic Activity Regional Index (based on materials from the Samara region). Journal "Ekonomicheskie Nauki" (Economic Sciences). 6(67), 122-127. 